\title{
Effect of Ultrasound Debridement on Serum Inflammatory Factors and bFGF, EGF Expression in Wound Tissues
}

\author{
Qiuping Zou1, Weiping Wang2, Qinghua Li3, Jiean Liu1, Tianming Xu1 and Xinmin Zhao1
}

\begin{abstract}
Objective: To determine the effect of ultrasonic debridement on serum inflammatory factors of procalcitonin (PCT), highsensitivity C-reactive protein (hs-CRP), red blood cell deposition rate (ESR) content, and expression levels of wound tissue basic fibroblast growth factor (bFGF) and epidermal growth factor (EGF).

Study Design: An experimental study.

Place and Duration of Study: Department of Emergency, Dongguan People's Hospital, China, from February 2016 to February 2018.

Methodology: A total of 80 patients with limb flap repair were randomly divided into a control group and an observation group, with 40 cases in each group. Control group was treated with conventional surgical debridement, and the observation group was treated with ultrasound debridement technique. The effect was compared between two groups.

Results: On the 1st, $3^{\text {rd }}$, and $7^{\text {th }}$ days after flap repair, Numeric Rating Scale (NRS) scores in observation group were lower than those in control group (all $p<0.001$ ). On the $7^{\text {th }}$ day after the flap repair, serum levels of PCT, hs-CRP, and ESR were lower in observation group than those in control group (all $p<0.001$ ). On the $7^{\text {th }}$ and $12^{\text {th }}$ day after flap repair, expression levels of bFGF and EGF protein in the wound tissue of observation group were higher than those in control group (all $p<0.001)$. Infection with sinus tract formed after the flap repair in observation group was lower than that in control group $(\mathrm{p}=0.048)$.

Conclusion: Compared with conventional surgical debridement, ultrasound debridement technique can more effectively reduce postoperative inflammatory reactions, reduce postoperative wound infection, relieve pain in patients, promote the bFGF and EGF expression in the wound tissue.
\end{abstract}

Key Words: Ultrasound debridement, Flap repair, Limb wounds, Inflammatory factors, bFGF, EGF

\section{INTRODUCTION}

Open limb injury caused by trauma is likely to cause large tissue necrosis and skin and soft tissue defects. It has become a common traumatic disease clinically. 1 Repeated infections and incomplete debridement may easily lead to prolonged healing of wounds in patients with larger wounds.2,3 Most wounds require flap repair, and thorough and effective debridement is often required before flap repair.4,5 Debridement has always been an indispensable method to treat wounds and promote healing. Traditional surgical debridement is difficult to completely remove necrotic tissue in larger infectious wounds, resulting in lower bacterial clearance rate and greater damage. ${ }^{6}$ Ultrasound debridement is a currently increasing clinical debridement method to treat infected wounds. ${ }^{7}$ Ultrasound debridement and surgical

1 Department of Emergency, Dongguan People's Hospital, Dongguan, China

2 Department of Emergency, The First Affiliated Hospital of Sun Yet-sen University, Guangzhou, China

3 Department of Gynaecology and Obstetrics, Dongguan Hongmei Hospital, Dongguan, China

Correspondence: Qiuping Zou,Department of Emergency, Dongguan People's Hospital, Dongguan 523059, China

E-mail: dingpin75512@163.com

Received: May 18, 2018; Accepted: October 18, 2018 debridement are equally suitable for guideline-based treatment of chronic wounds. 8

Wound healing is a complex process involving a large number of cytokines and media. ${ }^{9}$ Basic fibroblast growth factor (bFGF) and epidermal growth factor (EGF) play an important role in wound healing, and their biological effects are to enhance tissue cell proliferation, and promote epithelial regeneration and angiogenesis. ${ }^{10}$

The objective of this study was to determine the effect of ultrasonic debridement on serum inflammatory factors of procalcitonin (PCT), high-sensitivity $\mathrm{C}$-reactive protein (hs-CRP), red blood cell deposition rate (ESR) content, and expression levels of wound tissue bFGF and EGF.

\section{METHODOLOGY}

This experimental study was conducted at the Department of Emergency, Dongguan People's Hospital, China, from February 2016 to February 2018. The study was approved by the Hospital Ethics Committee, and all patients volunteered to participate in the study. A total of 80 patients, undergoing limb flap repair, were selected as study subjects. Inclusion criteria were time from injury to hospital admission $<8 \mathrm{~h}$, with serious wound tissue damage and pollution that could not undergo flap repair in the first surgery; time from injury to hospital admission $>8 \mathrm{~h}$, with wound tissue necrosis and bone exposure that needed flap repair in the second surgery; and patients 
who were able to undergo late flap repair. Exclusion criteria were suffering from diabetes, immune system diseases and other basic diseases that affected wound healing; superficial, light infection and smaller defect wounds that could be directly sutured or skin graft closure after a short-term dressing treatment, without the need for flap repair; and with other severe combined injuries when injured. Patients were randomly divided into a control group and an observation group, with 40 cases in each group.

Before the flaps were transplanted to repair the wounds, both groups of patients were required to complete various examinations. The wound secretions were taken for bacterial culture and drug susceptibility testing. According to the results of drug susceptibility testing, sensitive antibiotics were applied and comprehensive systemic medication was used to control blood glucose and improve the general condition of the patient. The control group was treated with conventional surgical debridement: the necrotic tissue was gradually pruned and removed with the scalpel and tissue scissors. If lacunar secretions gathered, low drainage needed to be done as much as possible. The number of dressings needed to be increased in patients with more wound exudates to avoid aggravated infection. The number of dressings was one to three times per day; after the necrotic tissue of the wound was cleared, the infection was controlled, and fresh granulation began to grow, flap transplantation was done to repair the wounds. The observation group was treated with ultrasonic debridement technique with an ultrasonic debridement instrument, the surgeon put the sterile water for injection into the handle, rinsed the debrider and then put into the saline solution, placed the handle tip 1-mm away from the wound surface, and used the vaporific saline solution to wash the wound until fresh granulation tissue was exposed. The appropriate ultrasonic power for irrigation was selected according to the size of the wound, depth, degree of infection and how much wound necrotic tissue. The irrigation time was $30-120$ seconds and the single irrigation time was $<300$ seconds. The irrigation interval was determined according to the cumulative condition of the wound necrotic tissue. Daily or every other day, the flap was transplanted and repaired according to the wound infection control and granulation growth.

Numeric Rating Scale (NRS) was used to compare the degree of pain on the 1 st, $3^{\text {rd }}$, and $7^{\text {th }}$ days after flap repair in both groups. This scale consists of a total of 11 digits from 0 to 10 , and the patient describes the intensity of the pain with 11 digits from 0 to $10=$ painless, 1-3 = mild pain (pain does not affect sleep), 4-6 = moderate pain, $7-9=$ cannot sleep or awaken during sleep, and 10 for severe pain.

On the $7^{\text {th }}$ day after the flap was repaired, $3 \mathrm{~mL}$ of venous blood was collected from both groups of patients and centrifuged to collect serum. The levels of inflammatory cytokines PCT, hs-CRP and ESR were detected by enzyme-linked immunosorbent assay (ELISA).

On the $7^{\text {th }}$ and $12^{\text {th }}$ days after flap repair, Western blot was used to detect and compare the expression levels of bFGF and EGF protein in the wound tissue between the two groups. The specific method was: the wound tissue was weighed, cut, smashed, and added with appropriate amount of protein lysate $(1 \mathrm{~g}$ tissue $/ 2.5 \mathrm{~mL}$ lysate). After being fully homogenized, it was centrifuged to extract total protein. The protein was then loaded onto $10 \%$ SDS-polyacrylamide gel for electrophoresis, electroporation and incubation with nitrocellulose (NC) membrane for rabbit-derived bFGF, EGF primary antibody, overnight at $4^{\circ} \mathrm{C}$. The tris-buffered saline (TBS) was used to wash it and incubate the goat anti-rabbit secondary antibody, and the film was developed and fixed. In addition, the incidence of infection after flap repair was observed in both groups.

SPSS version 21.0 software was adopted for data statistical analysis, measurement of data showed in Mean $\pm S D$, and examined by independent sample t-test. Enumeration data was represented by $\mathrm{n}(\%)$, and $X^{2}$ test was adopted to examine them. Results were considered significant at $p<0.05$.

\section{RESULTS}

Among the 80 patients, there were $45(56.25 \%)$ males and $35(43.75 \%)$ females, aged $20-53$ years, mean age $40.51 \pm 2.67$ years. There were $30(37.5 \%)$ cases of machine twists, $22(27.50 \%)$ cases of heavy weight bruises, $28(35.00 \%)$ cases of car accident injuries, $24(30.00 \%)$ cases of forearm injuries, $29(36.25 \%)$ cases of hand injuries, $19(23.75 \%)$ cases of leg injuries, and $8(10.00 \%)$ cases of foot injury. There were 59 $(73.75 \%)$ cases with injury time shorter than 8 hours and $21(26.25 \%)$ cases with injury time longer than 8 hours.

On the 1 st, $3^{\text {rd }}$, and $7^{\text {th }}$ days after flap repair, the NRS scores in the observation group were lower than those in the control group (all $p<0.001$, Table I). On the 7 th day after the flap repair, the serum levels of inflammatory cytokines PCT, hs-CRP, and ESR were lower in the observation group than those in the control group (all $p<0.001$, Table II). On the $7^{\text {th }}$ and $12^{\text {th }}$ day after flap repair, the expression of bFGF and EGF protein was found in the wound tissue of both groups, and the expression levels of bFGF and EGF protein in the wound tissue of observation group were higher than those in control group (all $p<0.001$, Table III) .

In the observation group, one case $(2.50 \%)$ had infection with sinus tract formed after the flap repair. In the control group, six cases $(15.00 \%)$ had infection with sinus tract formed after flap repair. There was statistical difference between the two groups $(p=0.048)$. 
Table I: Comparison of NRS scores.

\begin{tabular}{l|c|c|c}
\hline Parameters & $\begin{array}{c}\text { Control group } \\
(\mathrm{n}=40)\end{array}$ & $\begin{array}{c}\text { Observation group } \\
(\mathrm{n}=40)\end{array}$ & p-value \\
\hline $\begin{array}{l}\text { NRS scores on the 1st day } \\
\text { after flap repair }\end{array}$ & $6.51 \pm 1.45$ & $4.67 \pm 1.36$ & $<0.001$ \\
\hline $\begin{array}{l}\text { NRS scores on the 3rd day } \\
\text { after flap repair }\end{array}$ & $4.05 \pm 0.72$ & $2.93 \pm 0.43$ & $<0.001$ \\
$\begin{array}{l}\text { NRS scores on the } 7^{\text {th }} \text { day } \\
\text { after flap repair }\end{array}$ & $2.73 \pm 0.53$ & $1.18 \pm 0.38$ & $<0.001$ \\
\hline
\end{tabular}

Table II: Comparison of serum inflammatory factors contents on the $7^{\text {th }}$ day after flap repair.

\begin{tabular}{l|c|c|c}
\hline Parameters & $\begin{array}{c}\text { Control group } \\
(\mathrm{n}=40)\end{array}$ & $\begin{array}{c}\text { Observation group } \\
(\mathrm{n}=40)\end{array}$ & p-value \\
\hline PCT $(\mathrm{ng} / \mathrm{mL})$ & $6.67 \pm 0.45$ & $3.91 \pm 0.79$ & $<0.001$ \\
$\mathrm{hs}-\mathrm{CRP}(\mathrm{mg} / \mathrm{L})$ & $9.27 \pm 1.18$ & $6.35 \pm 0.73$ & $<0.001$ \\
ESR $(\mathrm{mm} / \mathrm{h})$ & $11.06 \pm 1.14$ & $8.42 \pm 0.65$ & $<0.001$ \\
\hline
\end{tabular}

Table III: Expression level of bFGF and EGF protein in wound tissue of different groups at different time points.

\begin{tabular}{l|c|c|c}
\hline Parameters & $\begin{array}{c}\text { Control group } \\
(\mathrm{n}=40)\end{array}$ & $\begin{array}{c}\text { Observation group } \\
(\mathrm{n}=40)\end{array}$ & $\mathrm{p}$-value \\
\hline $\begin{array}{l}\text { Expression of bFGF protein } \\
\text { on the } 7^{\text {th }} \text { day after flap repair }\end{array}$ & $0.573 \pm 0.143$ & $0.822 \pm 0.215$ & $<0.001$ \\
\hline $\begin{array}{l}\text { Expression of bFGF protein } \\
\text { on the 12th day after flap repair }\end{array}$ & $0.894 \pm 0.136$ & $1.161 \pm 0.223$ & $<0.001$ \\
\hline $\begin{array}{l}\text { Expression of EGF protein } \\
\text { on the } 7^{\text {th }} \text { day after flap repair }\end{array}$ & $0.865 \pm 0.139$ & $1.217 \pm 0.304$ & $<0.001$ \\
\hline $\begin{array}{l}\text { Expression of EGF protein } \\
\text { on the 12th }\end{array}$ & $1.278 \pm 0.260$ & $1.795 \pm 0.448$ & $<0.001$ \\
\hline
\end{tabular}

\section{DISCUSSION}

The timely treatment of wounds can create favorable conditions for the wound repair of patients with larger wounds of limbs, saving the affected limb and reducing complications. ${ }^{11-12}$ Debridement is undoubtedly of great importance in the treatment of wounds. Ultrasound debridement technology applied to the wound treatment is to integrate low-frequency and high-energy ultrasonic loading microfluidic technology and produce specific effects on the organism through the cavitation effect, based on the principles of thermal and mechanical mechanics. ${ }^{13,14}$ For relatively complicated wounds, the rinse head of the ultrasonic debridement device can enter into the abscess cavity for thorough cavity irrigation, effectively eliminating bacteria, toxins and necrotic tissue without damaging the normal tissue. Therefore, it can reduce bacteria and toxins that inhibit the growth of granulation tissue, increase the local tissue blood flow perfusion and oxygen partial pressure in the wound, which is beneficial to stimulate the release of proinflammatory mediators and growth factors, accelerate the growth of granulation in wounds through multiple actions, promote wound healing and eventually achieve the therapeutic purpose of reducing the infection. ${ }^{15}$ Studies have shown that ultrasonic debridement is an effective, less invasive technique to combat wound infection. ${ }^{16}$
In the wound repair surgery, if the patient has postoperative infection, it will affect the postoperative recovery, and even lead to surgical failure. This study found that the number of cases of infection and sinus tract formation after skin flap repair was lower in the observation group than that in the control group. It indicated that ultrasound debridement technique is complete and can reduce postoperative infection. This conclusion is basically consistent with other research findings. 17

The level of serum inflammatory factors can reflect the degree of infection to a certain extent. PCT, hs-CRP, $E S R$, etc. are important inflammatory stress indicators. PCT is commonly used as a marker for judging infections in the body in clinical practice. Its content as a calcitonin precursor is low in normal conditions, but it is influenced by systemic inflammatory responses such as bacterial infections, endotoxins, and inflammatory cytokines. Next, the PCT will be produced and secreted in many tissues, and serum PCT level will rise rapidly. 18 hs-CRP is an acute reactive protein and its expression level increases dramatically after infection or traumatization of the body. It is a high-energy earlywarning factor in inflammatory reactions. ${ }^{19} \mathrm{ESR}$ is also commonly used in clinical testing of infections. When the body is in an infected state, inflammation, or tissue damage, its expression in the blood can rise rapidly. 20 The results of this study showed that on the $7^{\text {th }}$ day after flap repair, the serum levels of inflammatory cytokines PCT, hs-CRP and ESR were lower in the observation group than those in the control group. It suggested that ultrasonic debridement can reduce postoperative inflammatory reactions in patients, which may be a mechanism for reducing postoperative infection.

bFGF is a heparin-binding polypeptide with a variety of biological activities. Its typical role is to induce cell proliferation and morphological changes, and it also has a role in cell differentiation. 21 The main biological effects of EGF include the promotion of cell proliferation and regeneration of new skin cells. 22 The results of this study showed that on the $7^{\text {th }}$ and $12^{\text {th }}$ days after the flap repair, the expression of bFGF and EGF protein in the wound tissue of the observation group was higher than that of the control group. The ultrasonic debridement technique may promote the proliferation of wound cells and accelerate wound healing by increasing the expression of bFGF and EGF in the wound tissue.

\section{CONCLUSION}

Compared with conventional surgical debridement, ultrasound debridement technique can more effectively reduce postoperative inflammatory reactions, reduce postoperative wound infection, relieve pain in patients, and promote the bFGF and EGF expression in the wound tissue. 


\section{REFERENCES}

1. van Zanten MC, Mistry RM, Suami H, Campbelllloyd A, Finkemeyer JP, Piller NB, et al. The lymphatic response to injury with soft-tissue reconstruction in high-energy open tibial fractures of the lower extremity. Plast Reconstr Surg 2017; 139: 483-91.

2. Yeh HK, Fang F, Lin YT, Lin CH, Lin CH, Hsu CC. The effect of systemic injury score on the decision making of mangled lower extremities. Injury 2016; 47:2127-30.

3. Norman J, Gahtan V, Franz M, Bramson R. Occult vascular injuries following gunshot wounds resulting in long bone fractures of the extremities. Am Surg 1995; 61:146-50.

4. Appling WD, Patrinely JR, Salzer TA. Transconjunctival approach vs. subciliary skin-muscle flap approach for orbital fracture repair. Arch Otolaryngol Head Neck Surg 1993; 119:1000-7.

5. Djordjevic ML, Majstorovic M, Stanojevic D, Bizic M, Kojovic V, Vukadinovic V, et al. Combined buccal mucosa graft and dorsal penile skin flap for repair of severe hypospadias. Urology 2008; 71:821-5.

6. Horseman MA, Surani S. A comprehensive review of vibrio vulnificus: an important cause of severe sepsis and skin and soft-tissue infection. Int J Infect Dis 2011; 15:e157-66.

7. Koshy G, Kawashima Y, Kiji M, Nitta H, Umeda M, Nagasawa T, et al. Effects of single-visit full-mouth ultrasonic debridement versus quadrant-wise ultrasonic debridement. J Clin Periodontol 2005; 32:734-43.

8. Herberger K, Franzke N, Blome C, Kirsten N, Augustin M. Efficacy, tolerability and patient benefit of ultrasound-assisted wound treatment versus surgical debridement: A randomized clinical study. Dermatology 2011; 222:244-9.

9. Efron PA, Moldawer LL. Cytokines and wound healing: The role of cytokine and anticytokine therapy in the repair response. J Burn Care Rehabil 2004; 25:149-60.

10. Fujisawa K, Miyamoto $Y$, Nagayama M. Basic fibroblast growth factor and epidermal growth factor reverse impaired ulcer healing of the rabbit oral mucosa. J Oral Pathol Med 2003; 32:358-66.

11. Jichlinski $P$, Delacretaz GP. Urethral stricture vaporization with the KTP laser provides evidence for a favorable impact of laser surgery on wound healing. Proc Spie 1997; 3192: 3235-7.

12. Kloth LC. Electrical stimulation for wound healing: A review of evidence from in vitro studies, animal experiments, and clinical trials. Int J Low Extrem Wounds 2005; 4:23-44.

13. Danielle DGM, Tiosso-Tamburi R, Martinez EF, Napimoga MH, Peruzzo DC. Clinical and immunoinflammatory evaluation of one-stage full-mouth ultrasonic debridement as a therapeutic approach for smokers with generalized aggressive periodontitis: A short-term follow-up study. J Periodontol 2016; 87:1012-21.

14. Müller S, Huber H, Goebel G, Wimmer G, Kapferer-Seebacher I. Pain perception during debridement of hypersensitive teeth elicited by two ultrasonic scalers. Clin Oral Investig 2017; 21: 1559-64.

15. Nm RBA, Nc CDS, Araujo CF, Mathias IF, Taiete T, Viana Casarin RC, et al. Clarithromycin as an adjunct to one-stage full mouth ultrasonic periodontal debridement in generalized aggressive periodontitis: A randomized controlled clinical trial. J Periodontol 2017; 88:244-52.

16. Tewarie L, Chernigov N, Goetzenich A, Moza A, Autschbach R, Zayat $R$. The effect of ultrasound-assisted debridement combined with vacuum pump therapy in deep sternal wound infections. Ann Thorac Cardiovasc Surg 2018; 24:139-46.

17. Hiebert JM, Robson MC. The immediate and delayed postdebridement effects on tissue bacterial wound counts of hypochlorous acid versus saline irrigation in chronic wounds. Eplasty 2016; 16:e32.

18. Ghorbani G. Procalcitonin role in differential diagnosis of infection stages and non infection inflammation. Pak J Biol Sci 2009; 12:393-6.

19. Kim DH, Shim JK, Hong SW, Cho KR, Kang SY, Kwak YL. Predictive value of c-reactive protein for major postoperative complications following off-pump coronary artery bypass surgery: prospective and observational trial. Circ J 2009; 73: 872-7.

20. Lee JH, Lee JH, Kim JB, Lee HS, Lee DY, Lee DO. Normal range of the inflammation related laboratory findings and predictors of the postoperative infection in spinal posterior fusion surgery. Clin Orthop Surg 2012; 4:269-77.

21. Scharpfenecker M, Van DM, Liu Z, van Bezooijen RL, Zhao Q, Pukac L, et al. BMP-9 signals via ALK1 and inhibits bFGFinduced endothelial cell proliferation and vegf-stimulated angiogenesis. J Cell Sci 2007; 120:964-72.

22. Türeyen K, Vemuganti R, Bowen KK, Sailor KA, Dempsey RJ. EGF and FGF-2 infusion increases post-ischemic neural progenitor cell proliferation in the adult rat brain. Neurosurgery 2005; 57:1254-63. 